\title{
Inoculation Of Soil With Cadmium-Resistant Actinomycetes Flora Reduces Cadmium Accumulation In Rice (Oryza Sativa L.)
}

\author{
XUE Shengping *1, WANG Xiaohuan ${ }^{2}$ \\ ${ }^{1}$ College of Bioscience and Bioengineering, \\ Hebei University of Economic and Business 47 xuefu road, \\ Shijiazhuang, China 050061 \\ Xsp6210@heuet.edu.cn \\ 2 Hebei Denuo Commodity Inspection Technology Service Co. LTD \\ Xincheng Shop Village, Xincheng Shop Town, \\ Zhengding District, China Pilot Free Trade Zone China 050802 \\ Wxh15303213089@163.com
}

\begin{abstract}
The microorganism and other amendments were immobilized in pellet carrier as microbial reverse screening model and were applied to the simulated Cd contaminated soil. Microbial flora (Streptomycete XW8, Actinomycetes XW3, Actinomycetes XW5) reduces $C d$ accumulation in rice when combined with biochar, humic acid and Carbon silicon functional liquid fertilizer. Microbial flora (Bacteria XW6, Actinomycetes XW3, Actinomycetes XW5) has highest TF and raises the bioavailability of $C d$ in soil. But Bacteria XW6 activate $C d$ in soil, which is a premium candidate for application in phytoremediation Cd farmland contamination. The compatibility of microbial flora had a significant effect in Cd reduction.
\end{abstract}

Keywords: Cd farmland contamination, Screen model, Microbial flora, Bioremediation, Amendments.

(C) Copyright 2021 Authors - This is an Open Access article published under the Creative Commons Attribution License terms (http://creativecommons.org/licenses/by/3.0). Unrestricted use, distribution, and reproduction in any medium are permitted, provided the original work is properly cited.

\section{Introduction}

Heavy metal contaminated farmlands remediation techniques include purification (remediation of contaminated soil by plants and microorganisms), passivation (absorption of heavy metal elements by minerals), and hazard avoidance (conversion of contaminated soil by "alien soil"), by high efficiency and low cost functional materials.

Microbial remediation of heavy metal involves bioaccumulation, biosorption, biomineralization and biotransformation ${ }^{[1]}$. Continuous flow reactor, are feasible methods for both CRM screening and formula optimization. However, the screening use of these two methods is limited to a lot of media and poisonous substances.

*: XUE Shengping corresponding author

Abbreviations: cadmium (Cd), Cd-remediation microorganism (CRM), Cd tolerance strains (CTS), Translocation factor (TF).

In soil polluted by heavy metals, actinomycetes are the most abundant, many of which have the bioremediation of repairing heavy metals and promoting plant growth [2].The development of treatment strategies for Cd-contaminated farmlands is urgent, because the $\mathrm{Cd}$ contamination has been a serious concern in recent years worldwide.

Bioremediation has attracted increasing interests for its eco-friendliness. Currently, functional screening of Cd-remediation microorganisms(CRM) is associated with low throughput, prohibitive costs and unsafe strains [3]. Studies carried out in actinomycetes strains were focused on setting the optimum conditions to remove heavy metals from the edible part of an 
agricultural product grown in the soil. The application of microbial flora immobilized cells to pollution area is still in its preliminary stages. It is necessary to clarify the necessity and feasibility of compatibility flora.

- In this study, joint immobilization of microorganism-Cd-amendments in alginate beads is a screening model for stimulating plant-microorganismCd-soil-amendments interactions.

CRM screened by reverse model[4] from 8 kinds of heavy complex contaminated soil in Baiyin, Gansu Province, China, can tolerate $450 \mathrm{mg} / \mathrm{L} \mathrm{Cd}$. Pots experiments were designed to investigate the effect of immobilized gel ball made by CRM and Humic acid, biochar, attapulgite, on soil $\mathrm{Cd}$ availability and $\mathrm{Cd}$ uptake in rice.

This is the first report of the use of screen model by the immobilized gel ball embedded in complex remediation material by sodium alginate. This approach greatly speeds up the screening of CRM by scaling down the whole process of simulating ecologic state with plant, microorganism and contaminated soil together. Therefore, with this novel approach to screen, likelihood of discovering useful strains for farmland bioremediation is increased.

\section{Materials and Methods}

\subsection{Material}

Humic acid, biochar and attapulgite (produced in Linze, Gansu) were provided by Hebei Shijiazhuang Yubo Co., Ltd., Professor Zhou Jianbin of Nanjing Forestry University and Liu Xilin of Shanghai Lichang Environment Co., Ltd. Carbon silicon functional liquid fertilizer, presented by Sheng Jianwei of Zhongqing Co. Ltd .

Samples were collected from Minqin village, Baiyin, Gansu. Potted Cinnamon soil was collected from the east bank of Ye river in Pingshan county, Hebei Province. Latitude $38^{\circ} 4$ ' north, longitude $114^{\circ} 9$ ' east.

Nutrient Agar (NA), Nutrient Broth (NB), Gauss No1 medium, Potato Dextrose Agar (PDA), Columbia blood plate, Murashige \& Skoog Medium (MS) purchased from Haibo biotechnology Co. Ltd China.

\subsection{Method}

Microbial screening model is consists of seed, soil, heavy metal and amendments. The matrix solution was prepared by mixing alginate and attapulgite-biocharhumic acid in media in the following way. The heavy metal contaminated soil and its leached liquid were used in the bioencapsulation process. Heavy metal contaminated soil leaching solution were made according to mass ratio of soil and water 1:1, sodium alginate, xanthan gum, heavy metal pollution of soil, attapulgite, biochar, humic acid, NB, MS and Gauss No1 medium to join in the leaching solution in proportion, mixing to join in mixture quality score is $1-2 \% \mathrm{CaCl} 2$. The matrix mixture was transferred to the conical flask with rice seed soaked in water for $12 \mathrm{~h}$ then sterilized in $2 \%$ sodium hypochlorite solution for $15 \mathrm{~min}$, the conical flask were incubated at $30^{\circ} \mathrm{C}$ for $48 \mathrm{~h}-96 \mathrm{~h}$. Cd tolerance strains (CTS) were isolated from germinated rice rhizosphere, the growing colonies were repeatedly inoculated onto a new NA, PDA, Gauss No1 medium plate containing the same and increased level of $\mathrm{Cd}$ concentration respectively. Finally, CTS were selected for further studies.

Bioencapsulation process. All the material used for the bioencapsulation process ${ }^{[5]}$ was previously sterilised and the process was carried out under aseptic conditions. Three grams of sodium alginate were dissolved in $100 \mathrm{ml}$ of media composed of MS, NB and Gauss No1 medium in 1:1:1 and stirred for $30 \mathrm{~min}$ to obtain a homogeneous solution (viscosity of alginate at $3 \%$ solution: 34 centipoise). The composition of alginate-attapulgite-biochar-humic acid matrix was given as follows mass ratio $1: 1: 1: 1,0.4 \mathrm{~g}$, respectively, were added to the alginate solution. The matrices were then stirred for $30 \mathrm{~min}$ for homogeneity. The matrix mixture was transferred to the syringe $(50 \mathrm{ml})$. The matrix solution dropped into sterile calcium chloride ( $0.1 \mathrm{moL})$. The collected beads were placed on a filter paper in a Petri dish. Before application, Microorganism in calcium alginate gel beads were cultured for $24 \mathrm{~h}$, $150 \mathrm{rpm} / \mathrm{min}$ at $28^{\circ} \mathrm{C}$.

Adsorption of heavy metals by immobilized colloidal spheres is taken as Pilot Solution.

The simulated heavy metal wastewater was adsorbed by sodium alginate gel embedded pellets, and the blank pellets were used as the control. The pellets and microorganism were added to the heavy metal ion solution, and the oscillatory adsorption was carried out at a rotating speed of $120 \mathrm{r} / \mathrm{min}$ and a temperature of $30^{\circ} \mathrm{C}$. When the continuous determination of heavy metal ion content remains unchanged, and the adsorption equilibrium is considered to be reached, and the adsorption rate is calculated.

Morphological characteristics of actinomycetes. Inoculate actinomycetes along the line between the cover slide and the culture medium,Remove cover slides at $2 \mathrm{~d} 、 5 \mathrm{~d} 、 7 \mathrm{~d}, 10 \mathrm{~d}, 15 \mathrm{~d}$ regularly. The 
morphology of substrate and aerial mycelium, the spore chain morphology, spore emitting mode and morphological characteristics were observed under the microscope. The production of diffusible pigments in different media were checked.

Hemolytic Activity Test. Transparent ring around the lawn is hemolytic positive in Columbia blood plate. Incomplete hemolysis forms a grassgreen hemolytic ring, No ring, No hemolytic.

Quantification of cadmium tolerance were detected by disk diffusion method on NA, Gauss No1 medium respectively, When the inhibitory zone is less than $7 \mathrm{~mm}$, it is considered as CRM.

Viable count. The glue pellets were dissolved with $0.1 \mathrm{M}$ citric acid respectively to release the cell from gel, ten times serial dilution was used to count the viable and culturable cells in different samples.

Solid fermentation. Commercial potted substrate is used as solid medium. The quality criteria for the pot substrate are that the total content of $\mathrm{N}, \mathrm{P}$ and $\mathrm{K}$ is $2.89 \%$ and the content of water-stable particles is $55 \%$. Corn meal was $2 \%$, and the content of Gao No1 medium was $3.75 \%$. Medium initial moisture content $60 \%$; pH $6.5 \sim 7.0$. Filling quantity of $40 \mathrm{~g} / 250 \mathrm{ml}$ conical flask.

Pot experiment. Potted soil samples were collected from the surface layer $(0-20 \mathrm{~cm}$ in depth) of a cinnamon soil rice field on the east bank of Ye river in Pingshan county, Hebei Province, China. The $\mathrm{pH}$ of the soil is 6.8 and the chemical properties are as follows: organic matter (OM) $18 \mathrm{~g} / \mathrm{kg}$, cation exchange capacity (CEC) $1.52 \mathrm{~g} / \mathrm{kg}$, total $\mathrm{N} 2.71 \mathrm{~g} / \mathrm{kg}$, available $\mathrm{N}$ $130.74 \mathrm{mg} / \mathrm{kg}$, available total P $296.46 \mathrm{mg} / \mathrm{kg}$, available $\mathrm{K} 95.37 \mathrm{mg} / \mathrm{kg}$.

The content of heavy metal $\mathrm{Cd}$ added into the soil for this test was $0.5 \mathrm{mg} / \mathrm{kg}$. Super hybrid rice seed Y liangyou 900(T900) were used in the present study. The seeds of the rice were surface-sterilized in $2 \%$ sodium hypochlorite for $5 \mathrm{~min}$ and rinsed several times with sterile distilled water. The seeds were then soaked for $24 \mathrm{~h}$ at room temperature, germinated for 2 days, and sown in normal, Cd-free soil. After 30 days, seedlings with similar appearance and biomass were carefully transplanted into each pot (fifteen plants/pot).

A completely randomized design was used to determine the inoculation of CTS on the growth and Cd uptake of rice plants grown in the Cd-contaminated soil. Triplicate pots were used for each treatment, with each pot (36 cm in diameter and $30 \mathrm{~cm}$ in height) containing $20.0 \mathrm{~kg}$ of soil. The strains immobilized in glue beads were cultivated in the sterile medium for $24 \mathrm{~h}$ then immobilized glue beads was adequately mixed with the soil in each pot. Soil of No2 No3 No4 were inoculated with living immobilized glue beads follow as Table1, CK(No1) was inoculated with same amount of nonstrains immobilized glue beads, Before sowing, All treatments were applied with $630 \mathrm{~kg} /$ hectare humic acid, $4800 \mathrm{~kg} /$ hectare biochar, $75 \mathrm{~L} /$ hectare Carbon silicon functional liquid fertilizer.

Soils in the pots are left to stabilize for 2-3 weeks to achieve stabilization.

Table 1. The treatment of pot experiment.

\begin{tabular}{|l|l|l|l|l|}
\hline Trial No & 1 & 2 & 3 & 4 \\
\hline Actinomycetes XW3 & - & - & + & + \\
\hline ActinomycetesXW5 & - & - & + & + \\
\hline Bacterium XW6 & - & + & - & + \\
\hline Streptomycete XW8 & - & + & + & - \\
\hline Summary & 0 & 68 & 358 & 356 \\
\hline
\end{tabular}

Determination of $\mathrm{Cd}$ and Translocation factor

The extraction method of soil active Cd follow Hani [6]. Soil available $\mathrm{Cd}$ is extracted by $1 \mathrm{~mol}$ ammonium acetate from soil with a solid-liquid ratio of $1: 5,23{ }^{\circ} \mathrm{C}, 200 \mathrm{r} / \mathrm{min}, 1.5 \mathrm{~h}$, centrifuged at $5000 \mathrm{r} / \mathrm{min}$ for $15 \mathrm{~min}$, then filtered and supernatant was taken.

According to GB 5009.15-2014[7], the pretreatment samples of plants were processed by microwave digestion to extract the full Cd of plants.

The calculation formulas of the TF of the treated rice are as follows [8]:

$T F=C d$ content in the aboveground part of the plant/Cd content in the underground part of the plant (1)

$B C F=$ plant part $C d$ content/soil $C d$ content (2)

The performance of graphite furnace atomic absorption spectrometer (PE AA800) was adjusted to the best state: wavelength $283.3 \mathrm{~nm}, 228.8 \mathrm{~nm}$ slit $0.5 \mathrm{~nm}$, lamp current $5 \mathrm{~mA}$, drying temperature $120^{\circ} \mathrm{C}$, 20s. Cd standard liquid was absorbed $10.0 \mu \mathrm{g} / \mathrm{L}$, $20.0 \mu \mathrm{g} / \mathrm{L}, 40.0 \mu \mathrm{g} / \mathrm{L}, 60.0 \mu \mathrm{g} / \mathrm{L}, 80.0 \mu \mathrm{g} / \mathrm{L}, 10 \mu \mathrm{L}$ each, and injected into the graphite furnace. The absorption value was measured and the linear regression equation was calculated.

SPSS 22 statistical analysis software single factor ANOVA was used to analyze the correlation among data. 


\section{Result}

\subsection{Heavy Metal Pollution Index of Soil in Baiyin, Gansu Province, China}

Eight heavy metals data in soil of village Minqin in Baiyin, Gansu are shown in table 2, the two sampling points are 50 meters apart from each other, sample collecting zone is 60 meters away from and parallel to East groove. The distance between these two samples is close, but the data difference is large, especially copper, chromium. The heterogeneity of farmland soil pollution [9] also make it tricky to remediate. Content of $\mathrm{Cd}$ and As in Baiyin is above risk intervention value in $6.5<\mathrm{pH}<=7.5$ of national standard, so the farmland in this area will be forbidden to tillage [10]. Other soils were selected for pot experiment in this study.The disadvantage of standardization is that it is contrary to the heterogeneity of soil. It is suggested to establish a prediction model of the equilibrium relationship between soil and heavy metal elements in real time by using the influencing factors on soil background value.

Table 2. Heavy metal index of soil of Baiyin, Gansu.

\begin{tabular}{|l|l|l|l|l|l|l|l|}
\hline $\mathrm{Cd}$ & $\mathrm{Pb}$ & $\mathrm{Ni}$ & $\mathrm{Hg}$ & $\mathrm{As}$ & $\mathrm{Cr}$ & $\mathrm{Cu}$ & $\mathrm{Zn}$ \\
\hline 7 & 254 & 31.4 & $\begin{array}{l}0.40 \\
0\end{array}$ & 180 & 56 & 331 & 495 \\
\hline 6.4 & 303 & 45.9 & $\begin{array}{l}0.58 \\
8\end{array}$ & 138 & 102 & 172 & 434 \\
\hline 8.6 & 16.3 & 31.7 & 32.0 & 23.3 & 45.1 & 48.0 & 12.3 \\
\hline 0.3 & 120 & 100 & 2.4 & 30 & 200 & 100 & 250 \\
\hline 3.0 & 700 & no & 4.0 & 120 & 1000 & no & no \\
\hline$*$ & $*$ & No & No & $* *$ & No & $*$ & $*$ \\
\hline
\end{tabular}

\subsection{Resistance to Cd}

The diameter of bacteriostatic ring which has inhibit effect is between $11-16 \mathrm{~mm}$. Resistance to $\mathrm{Cd}$ of the Streptomycete XW8, Actinomycetes XW3, ActinomycetesXW5 is more than $350 \mathrm{mg} / \mathrm{kg}$.

While Streptomycete XW8, Actinomycetes XW3, Actinomycetes XW5 of Cd and BacteriumXW6 produced no hemolysis on whole blood agar plates. XW1、XW2、 XW4 form transparent hemolysis ring around the colony produced by culture on the culture medium. The hemolysis experiment is simple and feasible ${ }^{[11]}$, and it can screen out the unsafe strains at the beginning to avoid long ineffective labor.

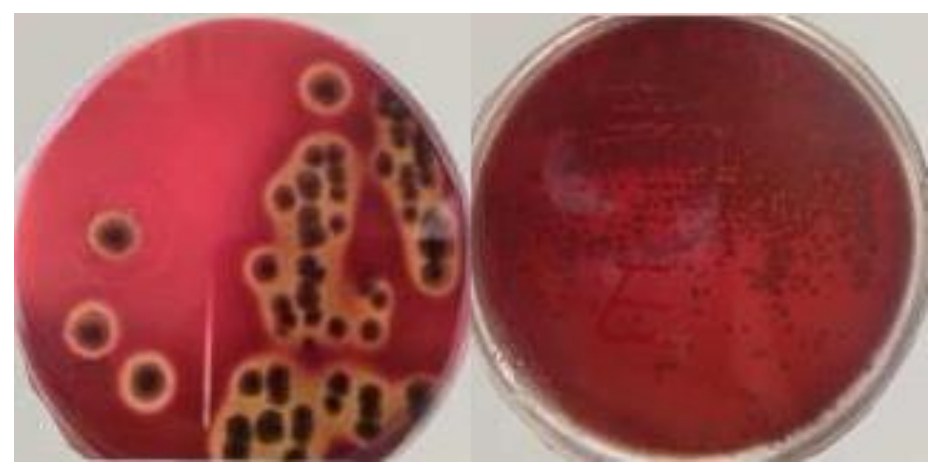

Figure 1. Hemolysis of strain positive (left) and negative (right).

Table 3. Cd inhibition zone ( $\mathrm{mm})$.

\begin{tabular}{|l|l|l|l|}
\hline & $350 \mathrm{mg} / \mathrm{kg}$ & $500 \mathrm{mg} / \mathrm{kg}$ & $1000 \mathrm{mg} / \mathrm{kg}$ \\
\hline XW3 & 6.9 & 19 & 19 \\
\hline XW5 & 6.8 & 19.5 & 19.5 \\
\hline XW6 & 6.7 & 16 & 16 \\
\hline XW7 & 6.7 & 21.5 & 21.5 \\
\hline XW8 & 6.7 & 19 & 19 \\
\hline Mean & 6.76 & 19 & 19 \\
\hline
\end{tabular}

\subsection{Immobilized Glue Beads}

At $4 \%$ sodium alginate, $0.4 \%$ attapulgite and $0.4 \%$ biochar, the pressure resistance of the glue bead was $33 \%$, round and black, as shown in Figure 2 on the left.

Rice sprouted on the screening model with Baiyin heavy metals soil, as shown in Figure 2 on the right.

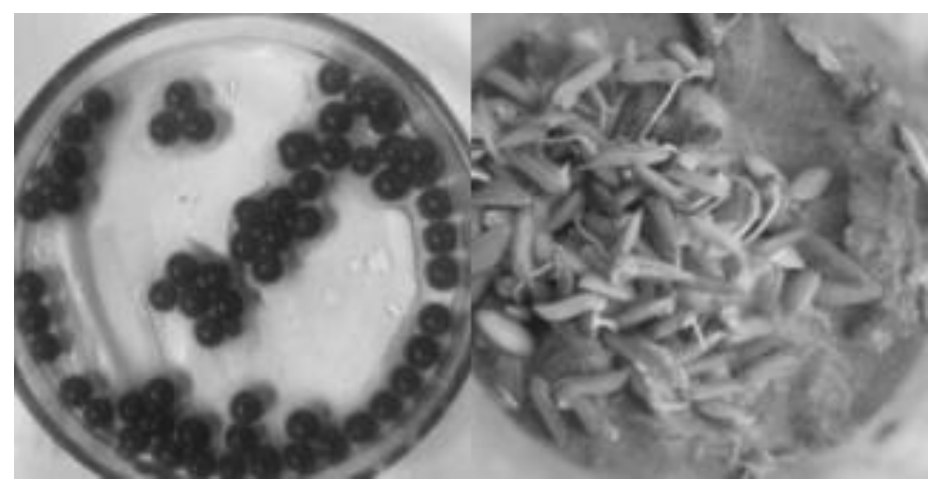

Figure 2. Immobilized glue beads (left), Microbial screening model (right). 
Table 4. Characterization of sodium alginate embedded pellets.

\begin{tabular}{|c|c|c|c|c|c|}
\hline $\begin{array}{l}\text { Ratio(SA } \\
: \text { ATP : } \\
\text { HA) }\end{array}$ & $\begin{array}{l}\text { Shape and } \\
\text { regularity }\end{array}$ & Color & $\begin{array}{l}\text { diam } \\
\text { eter( } \\
\mathrm{mm})\end{array}$ & $\begin{array}{l}\text { transpar } \\
\text { ence }\end{array}$ & $\begin{array}{l}\text { compr } \\
\text { essive } \\
\text { strengt } \\
\text { h }\end{array}$ \\
\hline $\begin{array}{ll}2.5: & 1.5 \\
: 0.8 & \end{array}$ & $\begin{array}{l}\text { Sphere, } \\
\text { uneven }\end{array}$ & black & $3-5$ & opaque & $40 \%$ \\
\hline $\begin{array}{ll}2.5: & 1.0 \\
: \quad 0.5 & \\
\end{array}$ & $\begin{array}{l}\text { Sphere, } \\
\text { even }\end{array}$ & black & 4 & opaque & $23 \%$ \\
\hline $\begin{array}{lll}2.5: & 0.5 \\
: & 0.2 & \\
\end{array}$ & $\begin{array}{l}\text { Irregular } \\
\text { sphericity, } \\
\text { large }\end{array}$ & grey & 6 & $\begin{array}{l}\text { Medium } \\
\text { transpar } \\
\text { ent }\end{array}$ & $31 \%$ \\
\hline $\begin{array}{lll}2.0: & 1.5 \\
: & 0.8 & \end{array}$ & $\begin{array}{l}\text { Sphere, } \\
\text { even }\end{array}$ & black & 4 & opaque & $26 \%$ \\
\hline $\begin{array}{ll}2.0: 1.0 \\
: 0.5 & \\
\end{array}$ & $\begin{array}{l}\text { Sphere, } \\
\text { even }\end{array}$ & $\begin{array}{l}\text { dark } \\
\text { gray }\end{array}$ & 4 & opaque & $37 \%$ \\
\hline $\begin{array}{lll}2.0: & 0.5 \\
: & 0.2 & \\
\end{array}$ & $\begin{array}{l}\text { Irregular } \\
\text { sphericity, } \\
\text { even }\end{array}$ & grey & 5 & $\begin{array}{l}\text { Medium } \\
\text { transpar } \\
\text { ent }\end{array}$ & $20 \%$ \\
\hline $\begin{array}{ll}1.5: & 1.5 \\
: & 0.8\end{array}$ & $\begin{array}{l}\text { sphere or } \\
\text { oval, } \\
\text { Uneven }\end{array}$ & black & $4-5$ & opaque & $22 \%$ \\
\hline 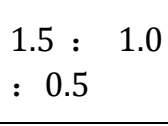 & $\begin{array}{l}\text { Irregular } \\
\text { sphericity, } \\
\text { Uneven }\end{array}$ & grey & $4-5$ & opaque & $17 \%$ \\
\hline
\end{tabular}

\subsection{Identification and characterization of CRM}

The Streptomycete XW8 spore filaments are straight, soft, pink, oval, irregularly round (FIG. 2).The air hyphae did not form the transverse septum at the initial stage, but the transverse septum and fracture appeared only when the long spore filament was mature.Aerial hyphae are mainly gray, gray and purple. Gause No1 agar produces melanin on the back of media. According to Bergey's Manual of Determinative Bacteriology 9th edition[12], XW8 was identified as Streptomyces preliminarily (Figure. 3).

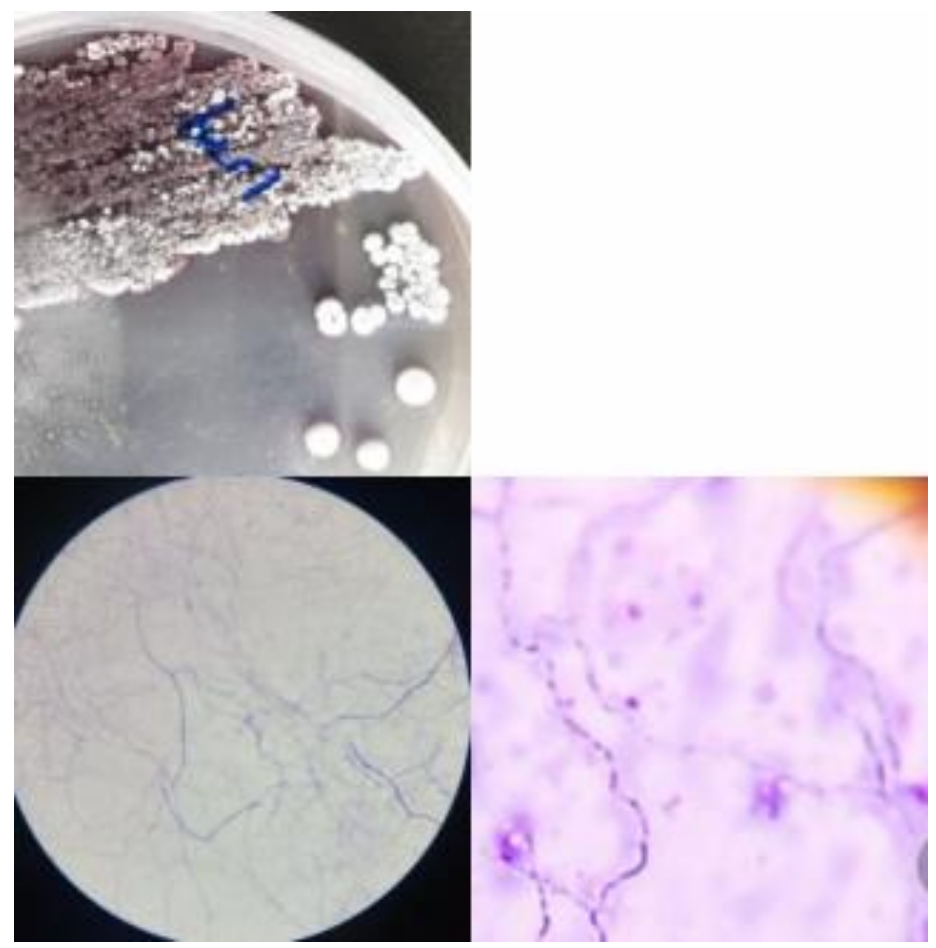

Figure 3. Streptomyces XW8 (left colon, middle 7d gram stain 400x, right 14d crystal violet stain 1600x).

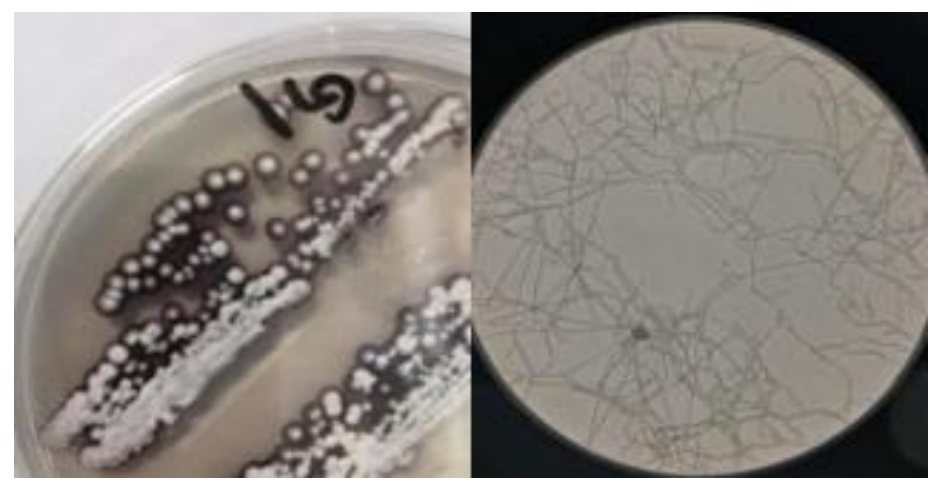

Figure 4. Morphology of colony and spore of Streptomyces XW5.

Culture characteristics of XW5 are shown in the figure4. After 7 days of culture, some aerial hyphae were separated, but no breakage and no spore filaments were found. By 15 days, found a long spore chain with long and straight, soft curved shape, spores for elliptic or irregular round, pink purple color. The colony is prosperous, round, with a raised and dry surface, covered with white villi, with smooth edges, and purple black pigment produced on the back of medium, as shown in Figure3. The bacterial colony characteristics of XW5 on other culture media are shown in Table 5. According to Bergey's Manual of Determinative Bacteriology 9th edition [12], XW5 strain was 
preliminarily identified as Streptomyce preliminarily (Figure 4.).

Table 5. Morphology of colony and spore of XW5 in different medium.

\begin{tabular}{|l|l|}
\hline medium & Morphology of colony and spore \\
\hline inorganic salt & $\begin{array}{l}\text { The colony is round and convex, with } \\
\text { white villi on the dry surface, smooth } \\
\text { edge of the colony, and purple } \\
\text { pigment in the medium.Aerial hyphae } \\
\text { without partition, long spore chain is } \\
\text { straight, slightly curved }\end{array}$ \\
\hline malt extract & $\begin{array}{l}\text { The colony is round and convex, the } \\
\text { surface is moist with folds, the colony } \\
\text { is grayish-green in color, diffusible } \\
\text { purple pigment. Mycelia no partition, } \\
\text { long spore chain is straight , slightly } \\
\text { curved }\end{array}$ \\
\hline ISP2 & $\begin{array}{l}\text { The colony is round and convex, with } \\
\text { white villi on the surface, then the } \\
\text { colony becomes moist with folds, and } \\
\text { the colony is purplish gray. Mycelia no } \\
\text { partition, long spore chains is straight } \\
\text { slightly curved } \\
\text { The colony is round and moist, white, } \\
\text { no pigment, the inflect mycelium has } \\
\text { no partition, No spore filament is } \\
\text { visible. }\end{array}$ \\
\hline NA
\end{tabular}

\subsection{Ecologicalc relationship between strain.}

Among XW3 、XW5 、XW6、XW8, pairwise combinations were lined parallell in pedish plate to check relationship each other (Figure6).

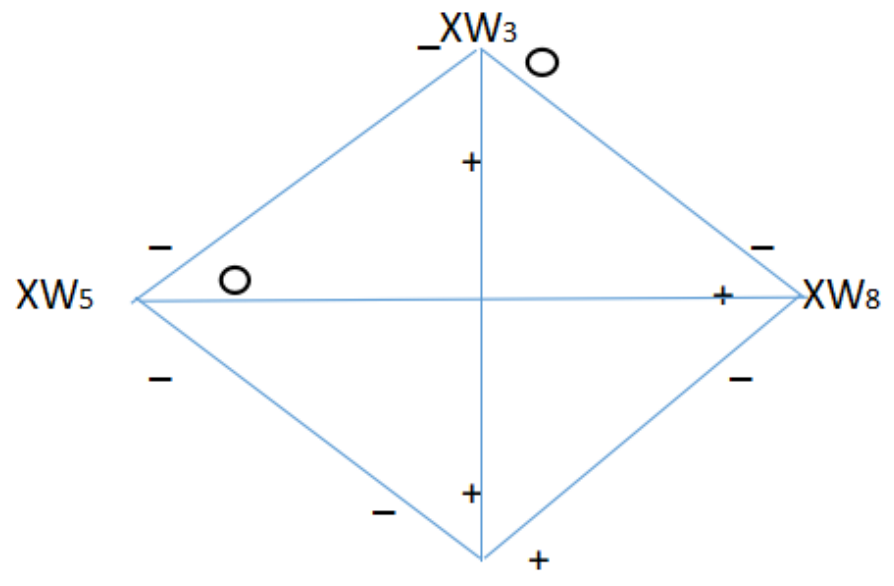

$\mathrm{XW}_{6}$
Figure 5. Ecological schematic diagram between strain (+promote,_inhibit, 0 no influence).

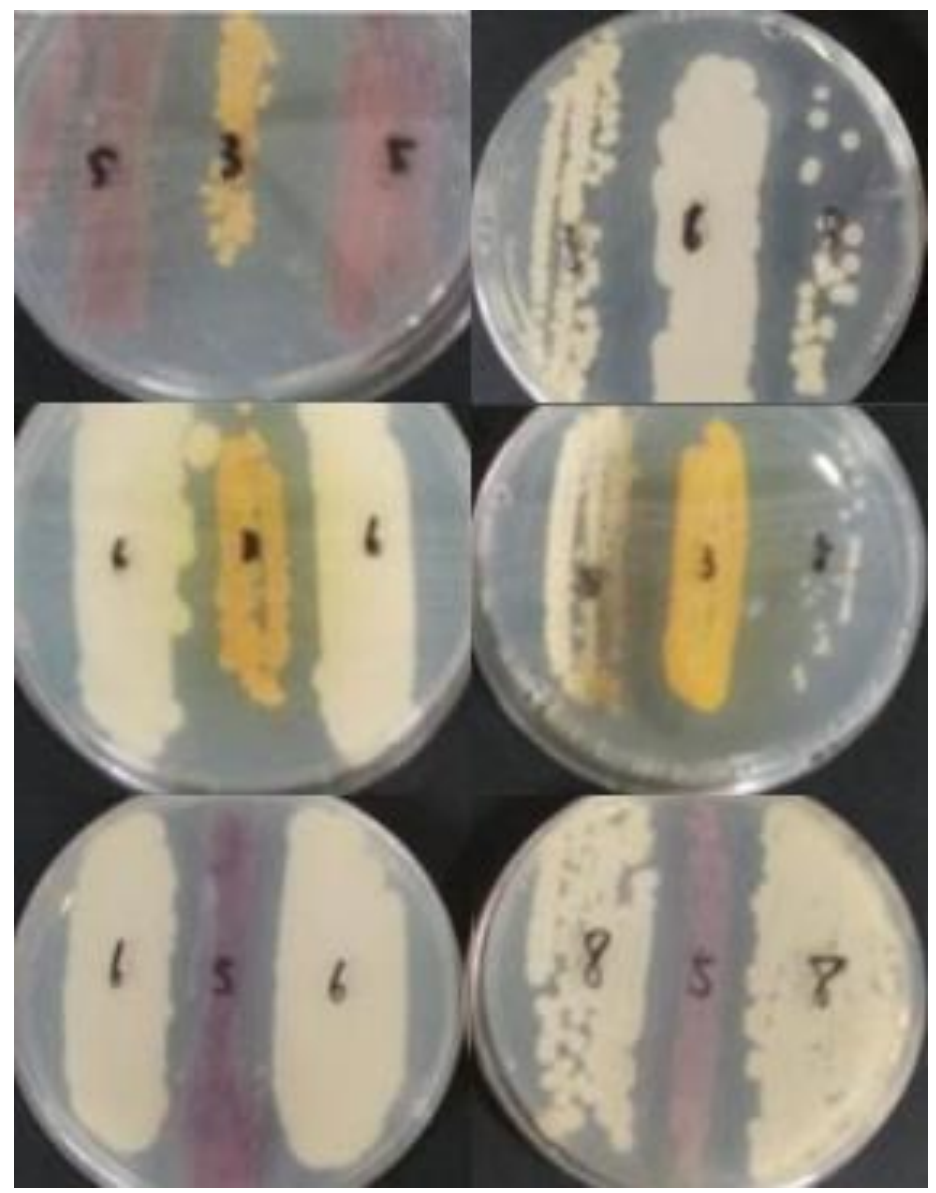

Figure 6. Ecological relationship between strains.

As show in Figure 6, from the trend of the line, the shape and width of microorganism lawn, draw a preminary conclusion that XW6 inhibit XW5 and XW8 but promote XW3 in Figure 5. XW3 promote XW6 growth, XW5 have no inhibit to XW8 and XW6. There are antagonism relationship between XW5 and XW6, also between XW5 and XW3. Quantitative study is needed to explore flora ecological relationship further.

Solid fermentation medium was prepared and mixed evenly with Commercial pot substrate. The total content of $\mathrm{N}, \mathrm{P}$ and $\mathrm{K}$ in Commercial pot substrate is $2.89 \%$, and the content of water-stable particles is $55 \%$. Corn meal was $2 \%$, and the content of Gao No1 medium was $3.75 \%$. Medium initial moisture content is $60 \%$ with pH $6.5 \sim 7.0$. Filling quantity is $40 \mathrm{~g} / 250 \mathrm{ml}$ conical flask and $300 \mathrm{~g}$ in Mushroom culture bag, thickness is $3-5 \mathrm{~cm}$, culture at $28^{\circ} \mathrm{C}$ for 7 days. The number of CFU was 1.011 billion/g by serial dilution 
vivable count method in Gas No1 medium. White spore is visible in conical flask (Figure7).

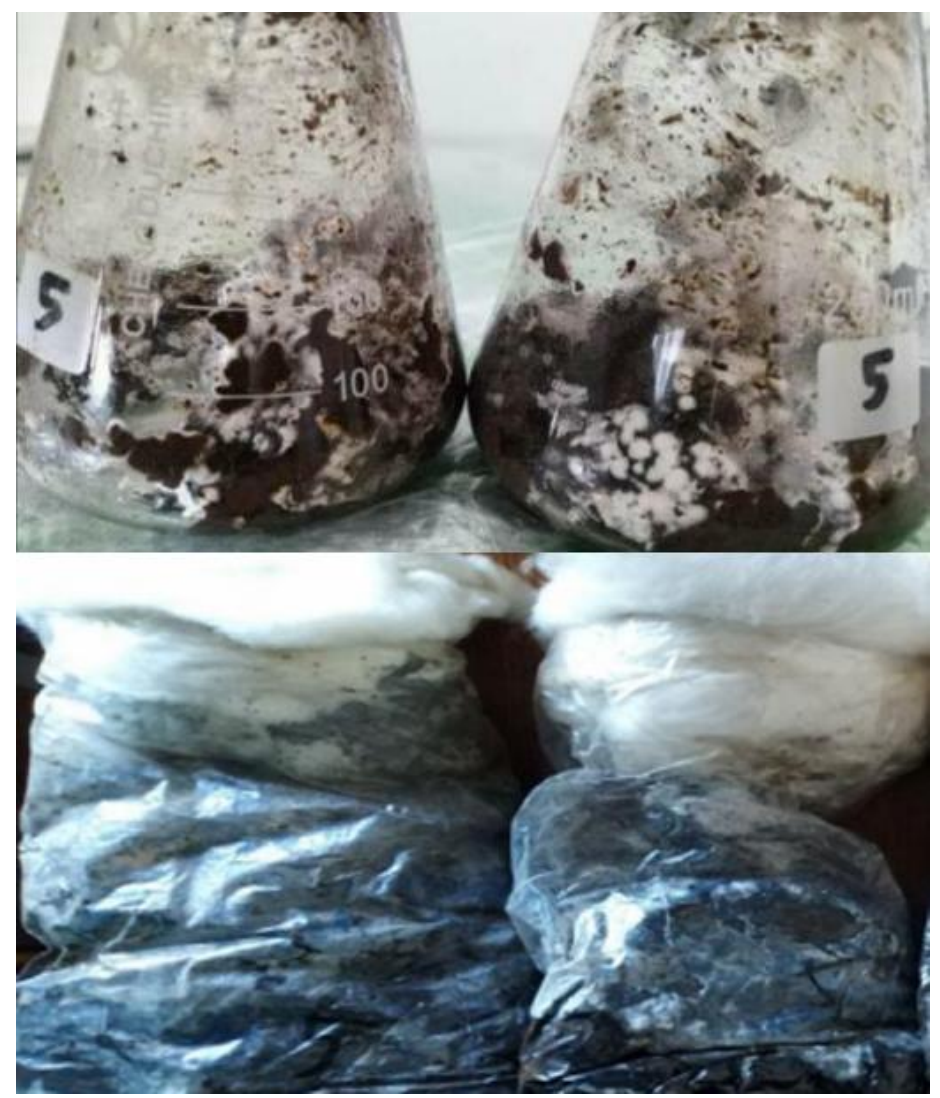

Figure 7. Solid fermention of XW5

Above: in conical flask, below: in Mushroom culture bag.

\subsection{Pot Experiment}

Selection of soil available cadmium extractant. Standard CdNO3 was added to potted soil, mostly in an exchange state, which was easy to be extracted by ammonium acetate, and the addition of highconcentration ammonium acetate effectively prevented the re-adsorption of $\mathrm{Cd}{ }^{[13]}$.Therefore, the active soil $\mathrm{Cd}$ was extracted with ammonium acetate in this cinnamon soil.

As illustrated in the table 6, all the indexes of No3 (Streptomycete XW8, Actinomycetes XW3, ActinomycetesXW5) were significantly different from the control $(\mathrm{P}<0.05)$, there were significant differences in the content of soil available $\mathrm{Cd}$ and $\mathrm{Cd}$ in the overground part between No3 with other groups. The TF of the No3 group was much higher than that of the other groups. Compared with the No2(Bacterium XW 6, Actinomycetes XW3, ActinomycetesXW5), only one strain of No3 was different, indicating that Bacterium XW6 activate $\mathrm{Cd}$, Soil available $\mathrm{Cd}$ content are almost the same in No2 and No3., so soil active Cd is not the determinant of crop cadmium safety.

Table6. Cd content, TF and BCF of rice under Cd stress (calculated by dry weight).

\begin{tabular}{|l|l|l|l|l|l|}
\hline & $\begin{array}{l}\text { belowgr } \\
\text { ound } \\
\text { part }\end{array}$ & $\begin{array}{l}\text { overgro } \\
\text { und part }\end{array}$ & $\begin{array}{l}\text { Soil } \\
\text { active } \\
\text { Cd }\end{array}$ & TF & BCF \\
\hline 1 & $\begin{array}{l}1.18 \pm 0.1 \\
\mathrm{a}\end{array}$ & $\begin{array}{l}0.05 \pm 0.0 \\
03 \mathrm{a}\end{array}$ & $\begin{array}{l}0.084 \pm 0 . \\
006 \mathrm{a}\end{array}$ & $\begin{array}{l}0.042 \pm 0 . \\
003 \mathrm{a}\end{array}$ & $\begin{array}{l}2.298 \pm \\
0.19 \mathrm{a}\end{array}$ \\
\hline 2 & $1.8 \pm 0.2 \mathrm{a}$ & $0.041 \pm 0$. & $0.054 \pm 0$. & $0.0228 \pm$ & $\begin{array}{l}3.589 \pm \\
0.4 \mathrm{a}\end{array}$ \\
\hline 3 & $0.89 \pm 0.1$ & $0.033 \pm 0$. & $0.043 \pm 0$. & $0.037 \pm 0$. & $\begin{array}{l}1.799 \pm \\
004 \mathrm{ab}\end{array}$ \\
& $\mathrm{ab}$ & $002 \mathrm{ac}$ & $003 \mathrm{ac}$ & $002 \mathrm{ab}$ & $0.2 \mathrm{ab}$ \\
\hline 4 & $0.035 \pm 0$. & $0.58 \pm 0.0$ & $0.040 \pm 0$. & $16.57 \pm 1$. & $1.199 \pm$ \\
$003 \mathrm{ac}$ & $01 \mathrm{a}$ & $0.17 \mathrm{ab}$ \\
\hline
\end{tabular}

For each column, values not marked with the same letter in superscript are significantly different at $\mathrm{p}<0.05$ (Duncan's).

\section{Discussion}

\subsection{Flora Relationship.}

Presupposes of the feasibility of compound formulations is no antagonism to each other. Necessity of formula is elucidated by the efficacy.

All the indexes of No3 (Streptomycete XW8, Actinomycetes XW3, ActinomycetesXW5) were significantly different from the control $(\mathrm{P}<0.05)$, there were significant differences in the content of soil available $\mathrm{Cd}$ and $\mathrm{Cd}$ in the overground part between No3 with other groups. The TF of the No4 group was much higher than that of the other groups. Compared with the No4(Bacterium XW 6, Actinomycetes XW3, ActinomycetesXW5), only one strain of No3 was different, indicating that Bacterium XW6 activate Cd, Soil available $\mathrm{Cd}$ content are almost the same in No4 and No3., so soil active Cd is not the determinant of crop cadmium safety.

Ueno A [14-15] proposed autochthonous bioaugmentation technology and its possible application to oil spills in 2006. Indigenous microorganisms are better able to adapt to the ecological conditions of the original soil and have better efficacy than Alien microorganism for colonization.

A single component cannot has all the mechanism, microbial flora complement each other and improve their resistance to pollutant. Bioremediation effect of No3 (Streptomycete XW8, Actinomycetes XW3, ActinomycetesXW5) is better than that of the No2, but both No2 and No3 is superior to No4. Streptomycete 
XW8 is supposedly the best one, particularly when applied in combination with Actinomycetes XW3, Actinomycetes XW5.

Microbial flora (Bacterium XW6, Actinomycetes XW3, Actinomycetes XW5) raises the bioavailability of $\mathrm{Cd}$ in rice soil. Clay mineral types, microorganisms, humus, $\mathrm{pH}$, heavy metal properties, soil enzymes and human activities all affect the bioavailability of heavy metals in soil. Bioremediation of heavy metals seems to be more efficacious when microbial flora are compatible. Like Chinese herbal compound, prescription principles of monarch, minister, assistant and guide, beside microorganism, there are biochar, humic acid, attapulgite. Alignate, silicon and phatase, which will influence ecological relationship each other. Physical parameter such as Moisturizing reduces transpiration which reduce $\mathrm{Cd}$ transport in xylem. The necessity and possibility of compatibility of formula, its usage and dosage must be studied. Reasonable dosage form of the embedding rubber ball can ensure the effect of repair, and is also an important factor affecting the stability of the effect in field. Immobilization glue bead increase the size, strength and $\mathrm{Cd}$ in magnetic immobilization could be removed from farmland.

\subsection{Actinobacteria Advantage.}

Actinobacteria would be excellent candidates for these microbial flora because of their proven versatility and abundance in the environment, microbial flora are robust, stable, and with synergistic activity to remove Cd and complex pollution [16-17].

Fungi appeared to be much more tolerant to As (III) than bacteria and actinomycetes[18]. But actinomycetes is much more tolerant to Cd than Fungi (Article publish later)

Actinobacteria is belong to PGPR ( Plant Growth Promoting Rhinoacteria). Mechanism of CRM to reduced cd content in Rice is as follows:

(1) Cells and their products of CRM immobilized cd.

(2) Cd absorb by root of rice is reduced for the less available cd in rhizosphere soil because of (1).

(3) Plant hormones produced by PGPR increase biomass to dilutes cd content of rice.

(4) Finally to the result of reduced cd accumulation in overground part of plant.

The Mechanism of CRM in this paper need to study further.

\subsection{Immobilization.}

For simulating complex interactions among plants and microorganisms and soil entrapped in a gel matrix, the immobilization reverse screening model is high-efficiency and low-cost to get CRM [19]. Gel polymerization or ion cross-linking forms a network with holes, where microorganisms are entrapped to immobilization.

Silicon can form a hard silicified cell on the surface of stems and leaves, reducing heavy metal pollution. Phytase in Carbon silicon functional liquid fertilizer can increase the activity of soil phosphatase and increase the content of phosphorus [20], which passivate $\mathrm{Cd}$ to phosphate by biomineralization. Biochar and humic acid [21-24] increased soil organic matter and nutrient as well as the survival of the place, to ensure the distribution of microbial colonization in time [25]. HA/FA/TA enhanced Cd (II) adsorption at low $\mathrm{pH}$ but hindered adsorption at high $\mathrm{pH}$ [26]. The application of multiple amendments is the reason for the success in this study.

Cd remediation need good seed, good method and good farmland. Hybrid rice, used in this study, has high output, and more resistant to cd, get more biomass in low Cd content but opposite in high Cd content [27]. Pollution-safe cultivars of rice could not exist when $\mathrm{Cd}$ pollution is very serious.[28]

Model can be used to stimulate, predict and control Cd pollution of farmland. [29]. The cd content of crops is a function of three factor which is cd content in soil, Crop types and its absorption characteristics ,soil property [30].

$Y=f$ (cd content in soil, Crop types and its absorption characteristics, soil property) (3)

China's rice cadmium limit standard $(0.2 \mathrm{mg} / \mathrm{kg})$ is stricter than that of Codex Alimentarius Commission and Japan $(0.4 \mathrm{mg} / \mathrm{kg})$. There is a technical bottleneck to take the reduction of cadmium content in total $\mathrm{Cd}$ value of both soil and crop and as the remediation standard. Chemical form of Cadmium in soil is single and steadfast, If Flux keep balance, the soil background value of $C d$ is same with total $C d$ value, Although value of soil active cadmium is superior to total cadmium, but the extraction method cannot be unified due to the difference of soil types, so lost the standard premise.

Quantification index is single set of goals of soil and agriculture product, Unquantifiable index will be changed with space-time such as long-acting, ecological safe and biodiversity, So control to quantification index is not guaranteed for control of unquantifiable index. 
How to integrate the goals at different levels of complex giant system, will be challange for us.

HSAB theory [31-32] indicates that Soft Acids combines well with soft Bases (HSAB). The composition of microorganism and organic matter is mostly soft alkali, which combine well with $\mathrm{Cd}$ and pb that are soft acid. Compounds bound between hard acid and hard bases or soft acid to soft bases are more stable. Biological and organic materials contain more weak base components. $\mathrm{Cd}$ in Compounds bound between soft acid to soft bases are less available for its insoluble in water.

Remediation technology of Non-renewable farmland should be gentle and no destructive, remediation technology by microbial and some organic material is green.

Table 7. Selectivity of metal ions by functional groups in biological systems [33].

\begin{tabular}{|l|l|l|}
\hline $\begin{array}{l}\text { varietie } \\
\text { metal of } \\
\text { ions }\end{array}$ & $\begin{array}{l}\text { ions and functional } \\
\text { groups bond to soft } \\
\text { metal } \\
\text { ions(Hg2+Cd2+Pb2+A } \\
\mathrm{u} 2+)\end{array}$ & $\begin{array}{l}\text { The ions and } \\
\text { functional groups } \\
\text { bond to hard metal } \\
\text { ions(Na+Mg2+Ca2+ } \\
\mathrm{K}+\text { ) }\end{array}$ \\
\hline $\begin{array}{l}\text { function } \\
\text { al group }\end{array}$ & $\begin{array}{l}\mathrm{CN}-\mathrm{R}-\mathrm{S}-\mathrm{SH}-\mathrm{NH} 2 \\
\text { imidazole(S/N- } \\
\text { containing functional } \\
\text { group) }\end{array}$ & $\begin{array}{l}\text { OH- HPO42- CO3- } \\
\text { R-COO- } \\
\text { =C=O(oxygen- } \\
\text { containing } \\
\text { functional group) }\end{array}$ \\
\hline bond & covalent bond & ionic bond \\
\hline
\end{tabular}

Positive attitude of farmer is important; if mediation could benefit the famer, they will take over remediation of soil; Microbial inoculant play role of remedition agent and biofertilizer, whch is operable and make a profit, so shape the close loop.

\section{Conclusion}

1. Bacterium XW6 is a premium candidate for application in phytoremediation field

2. Simple experimental model is useful for simulating complex interactions among plants and bacteria and soil entrapped in a gel matrix.

3. Microbial flora (Streptomycete XW8, Actinomycetes XW3, Actinomycetes XW5) reduces Cd accumulation in rice when used together with biochar, humic acid and Carbon silicon functional liquid fertilizer.

\section{Acknowledgements}

1.This work is sponsored by Hebei Provincial Higher Education Teaching Reform Research and Practice Project Gjxgk015 (2017), key project 2016KYZ01 of Hebei University of Economics and Business, and project C2015207019 of the Hebei Province Natural Fund.

2. Thanks SU Wenjing, Gansu Huayu Environmental Monitoring Technology Service Co., Ltd for the determination of soil samples Baiyin, Gansu, China and YAO Chunyi, Shijiazhuang ,China Customs Technical Center for the detection of soil and rice samples.

3. Thanks PAN Yinjie for review the paper.

4. Thanks ZHANG Mengxin and LI Kang afford experiment picture.

\section{References}

[1] Eileen Schütze, Michael Klose, Dirk Merten, et al, "Growth of streptomycetes in soil and their impact on bioremediation". Journal of Hazardous Materials, vol267, pp.128-135, 2014.

[2] Analia Alvarez, Juliana Maria Saez, José Sebastian Davila Costa, et al, "Actinobacteria: Current research and perspectives for bioremediation of pesticides and heavy metals". Chemosphere, vol166, pp.41-62, 2017.

[3] Samakshi Verma, Arindam Kuila, "Bioremediation of heavy metals by microbial process". Environmental Technology \& Innovation, vol14, pp.1-11, 2019.

[4] XUE Shengping, TIAN Zhenhua, LI Weiqian, ZHAI Yaoyao, LI Chengmin, MA Yujie, "Screen method of probiotics that mimic microecology, composite agent for soil remediation". CN Patent 201810983694.3, August 27, 2018.

[5] Luz E. Bashan, Yoav Bashan, "Joint Immobilization of Plant Growth-Promoting Bacteria and Green Microalgae in Alginate Beads as an Experimental Model for Studying Plant-Bacterium Interactions", Applied and environmental microbiology, vol74, No.21, pp6797-6802, 2008.

[6] Hani, "Reasons to use neutral solution to assess the metal impact on plant and soil". Presented at Proc of 12th Congress of soil sci soc Canada. 1985, pp4249.

[7] The National Health and Family Planning Commission of the People's Republic of China, GB5009.15-2014 National food safety standards 
Determination of cadmium in food. 2014. (In Chinese)

[8] Gu H H, Qiu H, Tian T,et al, "Mitigation effects of silicon rich amendments on heavy metal accumulation in rice(Oryza sativa L) planted on multi-metal contaminated acidic soil". Chemosphere, vol83, No.9, pp.1234-1240, 2011.

[9] Bin Chen, Shuduan Tan, Qingru Zeng, Andong Wang, Huabin Zheng, "Soil nutrient heterogeneity affects the accumulation and transfer of cadmium in Bermuda grass (Cynodon dactylon (L.) pers.)," Chemosphere, Vol 221, pp.342-348, 2019.

[10] Ministry of Ecology and Environment of the People's Republic of China, GB 15618-2018 State Administration of Markets. Soil environmental quality, Risk control standard for soil Contamination of agricultural land[S]. 2018. (in Chinese)

[11] Goebel, W., Chakraborty, T. and Kreft, J., "Bacterial Hemolysins as Virulence Factors". Antonie van Leeuwenhoek, vol54, No.5, pp.453-463, 1988.

[12] Holt, J.G. Bergey's manual of determinative bacteriology. 9th Edition, Lippincott Williams and Wilkins, Baltimore. 1994.

[13] Zou S M, Du R Y, Wen D, et al, "Enrichment characteristics analysis and assessment on heavy metal contamination of different vegetables “. Ecology and Environment Science, vol26, No.4, pp.714-720, 2017.(in Chinese).

[14] A Ueno,Y Ito, I Yumoto,H Okuyama, "Isolation and characterization of bacteria from soil contaminated with diesel oil and the possible use of these in autochthonous bioaugmentation". World Journal of Microbiology and Biotechnology, vol23, pp17391745, 2007.

[15] Ueno A, Ito Y, Yamamoto Y, Yumoto I, Okuyama $\mathrm{H}$, 'Bacterial community changes in diesel-oilcontaminated soil microcosms biostimulated with Luria-Bertani medium or bioaugmented with a petroleum-degrading bacterium, Pseudomonas aeruginosa strain WatG", J Basic Microbiol, vol46, pp310-317, 2006.

[16] Gavrish E, Bolhnann A, Epstein S, Lewis K, “ A trap for in situ cultivation of filamentous actinobacteria", Journal of Microbiological Methods, vol72, No.3, pp257-262, 2008.

[17] Kiliç, N.K., Kürkçü, G., Kumruoglu, D., Donmez, G., " EPS production and bioremoval of heavy metals by mixed and pure bacterial cultures isolated from Ankara Stream", Water Sci. Technol. vol72, No.9, pp.1488-1494, 2015.
[18] Mikiya Hiroki, "Effect of arsenic pollution on soil microbial population", Soil Science and Plant Nutrition Vol 39, No 2, pp227-235, 1993.

[19] XUE Shengping,MENG Shengya,XIE Min, "Isolation and characterisation of lead-resistant bacteria from a reverse screen model of simulation soil rice culture", presented at Advances in Engineering Research (AER), vol 143, 6th International Conference on Energy and Environmental Protection (ICEEP ), 2017, pp.10291035.

[20] D. Menezes-Blackburn, N.G. Inostroza, L. Gianfreda, et al, "Phytase-producing Bacillus sp. inoculation increases phosphorus availability in cattle manure." Journal of Soil Science and Plant Nutrition, vol16, No.1, pp.200-210, 2016.

[21] Mad Zia-ur-Rehman, Muhammad Sabir, Muhammad Rizwan, Saifullah, Muhammad Nadeem, Chapter 13: Remediating Cadmium-Contaminated Soils by Growing Grain Crops Using Inorganic Amendments Soil Remediation and Plants, 2015, pp.367-396.

[22] Wang, Yan Li, Yiming Zhang, Yong Wei, Wei, "Effects of macromolecular humic/fulvic acid on $\mathrm{Cd}$ (II) adsorption onto reed-derived biochar as compared with tannic acid", International Journal of Biological Macromolecules, Vol 134, No1, pp 4355,2019 .

[23] Zhenguo Shena,b, Chunlan Liane, Yahua Chen, "Analysis of the long-term effectiveness of biochar immobilization remediation on heavy metal contaminated soil and the potential environmental factors weakening the remediation effect: A review", Ecotoxicology and Environmental Safety, vol207, pp111261, 2021.

[24] Wang, Yan Li, Yiming Zhang, Yong Wei, Wei. Effects of macromolecular humic/fulvic acid on $\mathrm{Cd}(\mathrm{II})$ adsorption onto reed-derived biochar as compared with tannic acid, International Journal of Biological Macromolecules, 2019, Vol134, No.1. Pages 43-55, 2019.

[25] Yu Y, Wan Y, Camara AY, Li H, "Effects of the addition and aging of humic acid-based amendments on the solubility of $\mathrm{Cd}$ in soil solution and its accumulation in rice", Chemosphere, vol196, pp.303-310, 2018.

[26] Liu Y, Tie B, Li Y, Lei M, Wei X, Liu X, Du H, "Inoculation of soil with cadmium-resistant bacterium Delftia sp. B9 reduces cadmium accumulation in rice (Oryza sativa L.) grains," Ecotoxicology and Environmental Safety, vol163, no.11, pp.223-229, 2018. 
[27] Wang Kairong, GONG Huiqun, "Comparative Studies on the Difference of the Uptake and Redstribution of Environmental $\mathrm{Cd}$ by Two Genic Rice", Agro-Environmental rotection, vol4, No176, pp145-149, 1996(in chinese).

[28] Francois M,Grant C,Lambert R'Sauv, "Prediction of cadmium and zinc concentration in wheat grain from soils affected by the application of phosphate fertilizers varying in $\mathrm{Cd}$ concentration", Nutrient Cycling Agroecosyste,vol83, No2, pp125-133, 2009.

[29] Hui Yua, Jun li, Wang Wei, Fang Jiangang, Yuana, Zhongyi Yang, "Cadmium accumulation in different rice cultivars and screening for pollution-safe cultivars of rice", Science of The Total Environment, vol370, No( 2-3), pp 302-309, 2006.

[30] MURRAY B,MCBRIDE,M B 'Cadmium uptake by crops estimated from soil total $\mathrm{Cd}$ and $\mathrm{pH}$ ”, Soil Science,voll67,No.1, pp62-67, 2002.

[31] E.-C. Koch, "Acid-Base Interactions in Energetic Materials: I. The Hard and Soft Acids and Bases (HSAB) Principle-Insights to Reactivity and Sensitivity of Energetic Materials", Propellants, Explosives, Pyrotechnics, vol30, No1, pp8, 2005.

[32] Pearson R G. Hard and Soft Acids Bases. Dowden:HutchingSon \& Ross Inc, 1973, pp187.

[33] YIN Hua, CHEN Shuona, YE Jingshao, PENG Hui, TANG Shaoyu., Microbial adsorbent. China science press, 2017, pp109 (in Chinese) 